\title{
Health Promotion and Diabetes Prevention in American Indian and Alaska Native Communities — Traditional Foods Project, 2008-2014
}

\author{
Dawn Satterfield, PhD \\ Lemyra DeBruyn, PhD \\ Marjorie Santos, MPH \\ Larry Alonso, MSN \\ Melinda Frank, MPH \\ Native Diabetes Wellness Program, Division of Diabetes Translation, CDC
}

Corresponding author: Dawn Satterfield, Division of Diabetes Translation. Telephone: 770-488-5285; E-mail: dxs9@cdc.gov.

\section{Summary}

Type 2 diabetes was probably uncommon in American Indian and Alaska Native (AI/AN) populations before the 1940s. During 2010 2012, AI/AN adults were approximately 2.1 times as likely to have diabetes diagnosed as non-Hispanic white adults. Although type 2 diabetes in youth is still uncommon, AI/AN youth (aged 15-19 years) experienced a 68\% increase in diagnosed diabetes from 1994 to 2004. Health disparities are related to biological, environmental, sociological, and historical factors. This report highlights observations from the Traditional Foods Project (2008-2014) that illustrate tribally driven solutions, built on traditional ecological knowledge, to reclaim food systems for health promotion and prevention of chronic illnesses, including diabetes.

\section{Introduction}

Before the 1940s, diabetes was probably uncommon among American Indians/Alaska Natives (AI/AN) (1). In 1940, only 21 cases of diabetes were identified among the Akimel O'odham people (Pima) living in the Sonoran Desert on the Gila River (2). In 2006, 38\% of Akimel O'odham adults aged $\geq 20$ years had type 2 diabetes (3). In 2001, one in 359 Navajo youth aged 15-19 years had diabetes and one in 2,542 developed diabetes annually (4).

During 2010-2012, AI/AN adults aged $\geq 20$ years were 2.1 times as likely to have diabetes diagnosed compared with non-Hispanic white adults (15.9\% versus $7.6 \%$ respectively) (5).The age-adjusted rate of diagnosed diabetes among AI/AN adults varied by region from $6.0 \%$ among Alaska Natives to $24.1 \%$ among American Indians in southern Arizona (5). From 1994 to 2004, diagnosed diabetes rates increased 68\% among AI/AN youth aged 15-19 (6) and 100\% from 1994 to 2007 among AI/AN young adults aged 18-34 (7). Young persons who develop type 2 diabetes are at risk for diabetes-related complications, including end-stage renal disease (ESRD), while they are young adults (8). During 2013-2014, approximately $17.5 \%$ of youth aged $2-19$ years were obese, a risk factor for type 2 diabetes, which has remained about the same since 2003-2004 (9). In 2009, 20.7\% of AI/AN children aged $2-4$ years were obese $(10)$.

CDC's Office of Minority Health and Health Equity selected the Traditional Foods Project's thematic analysis and discussion to provide an example of a program that builds awareness of health disparities and tribally driven solutions to address health promotion and diabetes prevention by reclaiming their traditional food systems and related physical activity and social support. Criteria for selecting this project are described in the Background and Rationale for this supplement (11).

\section{Diabetes and Social Determinants of Health}

Biologic explanations for disproportionate burdens of chronic illness, though strong and predictive, tend to focus on the behaviors of individuals rather than the risk-laden social conditions (e.g., income distributions and violation of human rights) that contributed to their development in the first place $(12,13)$. For diseases such as diabetes, attention to the social history is as important as learning the natural history (14). Physiologic stress responses have been associated with historical trauma (i.e., cumulative emotional and psychological wounding across generations, including the lifespan, which emanates from massive group trauma) (15) and adverse childhood experiences (ACE) (e.g., abuse and neglect, and serious household dysfunction, and premature death of a family member) (16). The ACE Study, a collaboration between CDC and Kaiser Permanente's Health Appraisal Clinic in San Diego, is one of the largest investigations ever conducted to assess associations between childhood maltreatment and laterlife health and well-being (16), including obesity (17-19) and chronic disease (20). Research has identified links between physiologic stress responses in childhood and neurologic changes to the brain that can affect the complex web of causation for chronic diseases and other threats (21-23). 
Social determinants of health $(\mathrm{SDOH})$ are defined as the conditions in which persons are born, grow, live, work, worship, and age that affect a wide range of health, functioning, and quality-of-life outcomes (24). SDOH include social, economic, and physical environments as "place," conditions that include economic stability, education, access to healthy foods, health care, patterns of social engagement, and sense of security and of well-being (24).

In 2010, an estimated 23\% of Native American families earned incomes below the poverty line (25), a SDOH linked to "place" (24). Food insecurity, defined as uncertain or limited access to enough foods for an active healthy life because of a lack of money or resources, affected $28 \%$ of Native households with children in 2008 , compared with $16 \%$ of U.S. households with children (26). Researchers have linked food insecurity to obesity in households with children (27), diabetes in adults (28), and poor glucose control for adults who have diabetes $(29,30)$. Food insecurity is found on many reservations where food deserts (i.e., rural, low-income residents must travel more than 10 miles to access supermarkets or grocery stores) are prevalent (31-33). On a reservation in the Great Plains, 40\% of families with children were food insecure. Much of the food available in homes was purchased at convenience stores on or near the reservation (33).

A first step in creating systemic, long-term changes to redress imbalances and promote health in $\mathrm{AI} / \mathrm{AN}$ communities is to build awareness of the complexities regarding the historic and contemporary context of policy, poverty, historical trauma, and food systems related to health disparities, including diabetes disaprities (34). Innovative models will likely be informed by traditional ecological knowledge, a natural science grounded in lifetimes of observation, experimentation, and adaptation (35).

\section{The Land - Place - as a Social Determinant of Health and of Tribally Governed Solutions}

Disruption of indigenous persons' relationships with their homelands, including land, language, culture, and religious beliefs, has been suggested to be "at the root of health disparities" (36). Certain public health leaders have noted that this connection to health disparities, including the diabetes epidemic in Native populations, has received little attention $(37,38)$. Indigenous persons had traditionally gathered and cultivated plants and hunted and fished on their lands (39). Even with the restricted access to their fertile lands through policy changes, including the reservation era, many tribes maintained a high-fiber diet based on traditional foods that fueled a physically active life $(39,40)$. However, industrial developments beginning in the mid-1900s on some tribal lands have further limited tribes' ability to harvest their traditional foods and curtailed the associated physical activity (39).

For centuries, the Pima-Maricopa and Akimel O'odham people had channeled the waters of the Gila and Salt Rivers in the Sonoran Desert in Arizona through irrigation systems that secured their foods (e.g., drought-hardy tepary beans and prickly pear cactus). By the 1950s, the rivers had been diverted for ranches and construction of the Coolidge Dam, and the land became unsuitable for farming (41). By 2006, 38\% of adults aged $\geq 20$ years had type 2 diabetes, a rate 5.5 times that of tribal people of the same heritage in Mexico (6.9\%), who continued to farm and consume food cultivated for generations (3). Currently, O'odham people living in Arizona who consume a traditional diet are less likely to develop type 2 diabetes than their peers who eat a modern-day diet (42).

In the 1940s and 1950s, the bottomlands of the Missouri River on the Fort Berthold Reservation, home of the Three Affiliated Tribes (Mandan, Hidatsa, and Arikara) and seven other Native communities, were flooded to accommodate the waters of the Garrison Dam (43-46). Approximately one fourth of the population of the Standing Rock Tribe had to evacuate their homes before the flood of approximately 160,000 acres (44). Many local foods, (e.g., wild turnips, berries, beans, wildlife, and medicinal plants) were lost as the bottomlands were flooded (43-45). By 2000, the prevalence of diagnosed diabetes in the area was approximately three times the rate for non-Hispanic whites (47).

Values, including stewardship of natural resources of land and water, are reflected in tribes' unique stories about their food systems $(45,46)$. The importance of flowing water is a common teaching; "Water is life," is often said in Native languages (48). In recent decades, many tribal nations are reclaiming the water and foods specific to their landscape, history, and culture $(34,46,48)$. Tribal nations are part of a global food sovereignty movement that maintains the rights of all persons to define their own policies and strategies for sustainable food and agriculture systems. La Via Camaesina, the International Indian Treaty Rights Council, and allies catalyzed the movement in the 1990s, presenting a declaration to the United Nations, which also stated that food sovereignty is a necessary condition to assure food security (49-51).

\section{History of the Traditional Foods Project}

In response to the epidemic of diabetes among Native persons, in 1997, Congress passed the Balanced Budget Amendment (Law 105-33) establishing the Special Diabetes Program for 
Indians (SDPI) (52), administered by IHS and guided by their Tribal Leaders Diabetes Committee (TLDC). During 1999-2000, approximately 400 tribal members representing 171 tribal nations helped inform planning. Their suggestions included creating stories for children about preventing diabetes, since there were few stories because diabetes had been largely unknown until recent decades, and incorporating traditional knowledge and culture alongside Western medicine (48).

Reports document encouraging health trends since SDPI was established in 1998, including sustained improvements in glucose and blood pressure control and reduced incidence of ESRD (53-55). From 2001 to 2013, ESRD prevalence among AI/ANs declined 29\%, the only instance of a significant decline in prevalence for a major racial group since ESRD care was implemented in 1973 (55).

CDC's National Diabetes Prevention Center, established in 1998 in part to complement the work of SDPI, was reorganized and named the Native Diabetes Wellness Program (NDWP) in 2004. Principles of practice were integral to program operations (48), including concepts of cultural humility (56) and tribally driven, community-based participatory approaches (57-59). In 2006, NDWP, in collaboration with IHS and TLDC, introduced the Eagle Books series for young children. The stories highlight the wisdom of traditional ways of health (e.g., harvesting healthy foods, physical activity, gratitude, generosity, stewardship, and courage) through the voices of animals (e.g., a wise eagle, garden-loving rabbit, and clever coyote) engaged in dialogue with eager-to-learn children $(48,60)$. The early grades $(\mathrm{K}-4)$ of the Diabetes Education in Tribal Schools (DETS) K-12 curriculum, Health is Life in Balance, led by the National Institutes of Health, CDC, IHS, and eight Tribal colleges and universities, features the Eagle Books stories. The DETS curriculum embeds the " 5 E's" of educational instruction (i.e., engagement, exploration, explanation, elaboration, and evaluation) $(61,62)$.

In 2008, CDC announced a 5-year funding opportunity entitled Using Traditional Foods and Sustainable Ecological Approaches to Promote Health and Help Prevent Diabetes in American Indian and Alaska Native Communities (i.e., Traditional Foods Project) informed by tribal leaders and earlier programming about the resonance of increasing traditional foods access with health promotion efforts (63). The project proposed to 1) support sustainable and evaluable ecologic approaches to reclaim traditional foods and physical activity; 2) encourage local practices that increase access to local foods and physical activity; 3) revive and create stories of healthy traditional ways to be remembered, retold, and talked about in homes, schools, and communities; and 4) engage community members to track success, participate in health promotion activities, explore diabetes in context with community history, and share stories of hope (e.g., radio, print, social media, and digital stories). Supported by funding from IHS following approval by TLDC and operations support from CDC, NDWP launched the Traditional Foods Project with 11 cooperative agreements with diverse tribal communities in September 2008. Additional funding was allocated by CDC in 2009, enabling the addition of more partners (Figure). Traditional Foods Project partners each received $\$ 100,000$ per year to implement their local programs. In 2012 and 2013, Traditional Foods Project partners and NDWP staff were invited to present to the CDC Tribal Advisory Committee, which recommended continuing the Traditional Foods Project for a year beyond the 5-year cycle. Partners applied for a sixth year of funding for 2014 by demonstrating their evaluation results and plans to sustain their native food systems.

\section{FIGURE. Location of Traditional Foods Project partners}

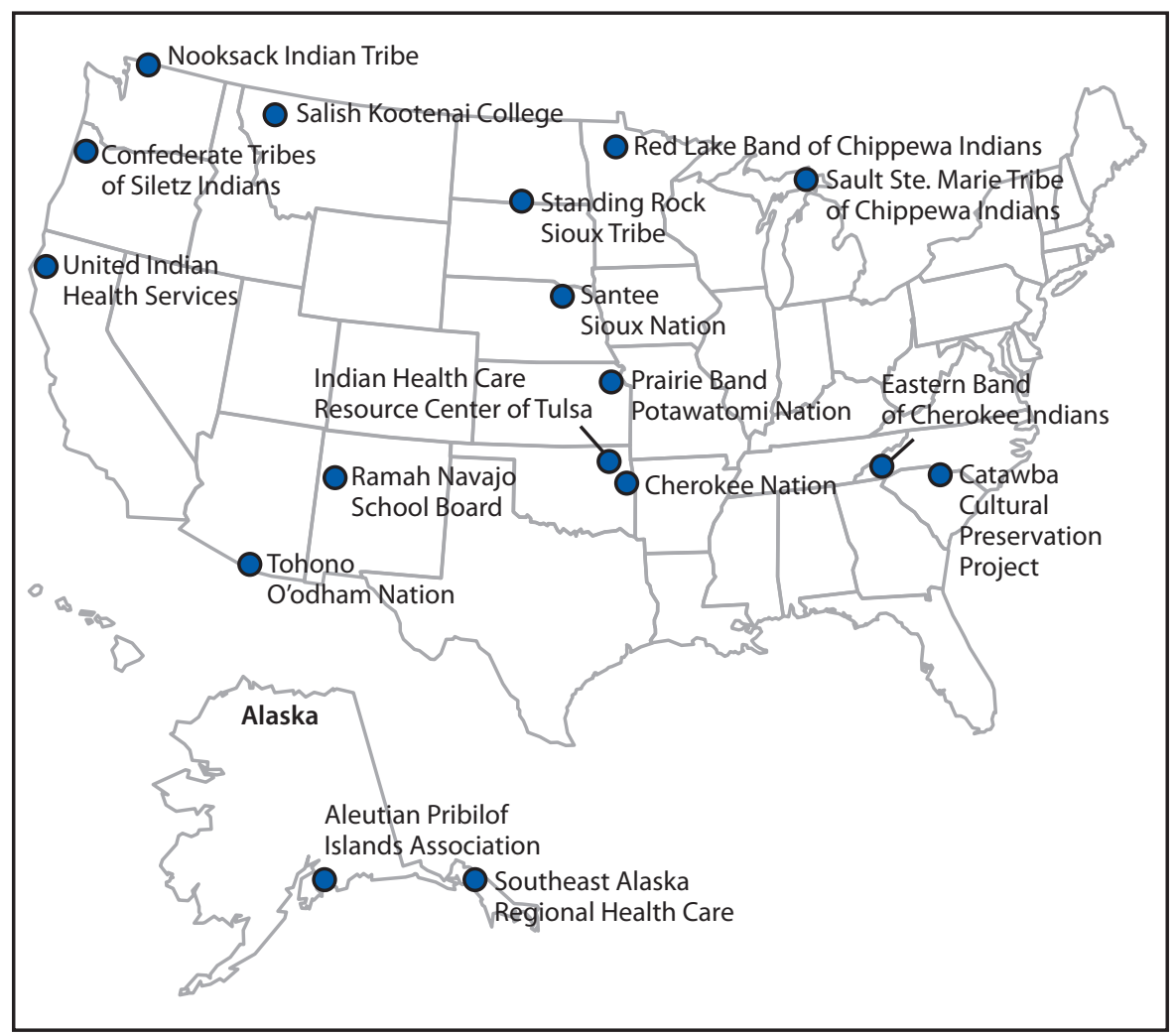




\section{Methods}

NDWP collaborated with Traditional Foods Project partners to evaluate the process ("how do we do this work effectively?"), methods ("how do we measure interventions to reclaim food systems in relation to health?"), and environmental outcomes (increased and sustained accessibility of traditional local healthy foods, physical activity and social support in relation to health) of the Traditional Foods Project. Quantitative data included measures of access to traditional foods, physical activity, and social support over time.

Ethnographic and qualitative data from tribal partner presentations, partner collaborations, monthly conference calls, and annual meetings described each programs' maturation, strategy development, accomplishments, barriers encountered, and adaptations made. Data reported by partners at 6-month intervals through the Traditional Foods Project's conclusion in September 2014 were gathered using Office of Management and Budget-approved shared data elements, an aggregate data evaluation tool; results are being analyzed by CDC.

\section{Discussion}

Early observations gleaned from this multifaceted evaluation and preliminary CDC analysis of the tool are promising. These observations include:

- Significance of land: Recognition of the importance of the land holds deep meaning for tribal members. Working with the land, or Mother Earth, is considered an honorable activity (64). This grounding observation was manifested as partners worked to strengthen tribal self-governance to secure land that helped to revive and sustain food systems and preserve subsistence practices and their homelands. Many programs provided workshops on cooking, hunting, gathering, fishing, and preserving foods and environmental stewardship.

- Interest in Native American food pathways and foodsheds: Tribal communities are leading a food sovereignty movement in North America to revive the foods specific to the landscape, history, and culture of their people (45). During the 6 years of the Traditional Foods Project (2008-2014), the momentum grew locally and nationally as partners aligned their efforts with the 2008 Farm Bill and created opportunities to operationalize the Agricultural Act of 2014 (65) related to the service of traditional foods in public facilities and the U.S. Department of Agriculture (USDA) Food Distribution Program on Indian Reservations (FDPIR), nutrition education, and physical activity (66). The momentum of the food sovereignty movement continued to grow as partners shared experiences and stories with other tribal programs. For example, Qaqamiigux: Traditional Foods and Recipes from the Aleutian and Pribilof Islands was published in 2014 by the Aleutian Pribilof Islands Association, a Traditional Foods Project partner (67).

- Respect for traditional knowledge: Wisdom to adapt to changing conditions, including rebuilding food systems that worked for thousands of years, is inherent in traditional ecologic knowledge. Persons develop traditional knowledge through direct personal experience with the land and its interrelationships. The knowledge is communicated orally and validated by generations who successfully manage "the commons" of shared land, language, foods, and culture (35).

- Consistency with traditional values: Messages and approaches grounded in traditional ways of knowing about health are consistent with cultural values. Values are reinforced through storytelling, gratitude for the gifts of the earth, and generosity in sharing harvested foods throughout communities. Stories and practices of gathering, growing, and harvesting with families are often remembered and shared, contributing to the description of persons' homelands as "resilient places of remembrance" (68).

- The role of elders as teachers of traditional knowledge fosters intergenerational relationships: Elders served as advisors to help guide program development. They taught traditional subsistence practices to youth, often naming foods and activities in their tribal language. The engagement of elders and youth strengthened social connections.

- Traditional foods facilitate dialogue about health. Partners agreed that traditional foods activities are a way to discuss health in tribal communities. Community members were drawn to messaging and activities that involved growing, harvesting, and preparing foods; sharing stories and traditional ecological knowledge; playing traditional games and dancing; and participating in talking circles. Educational materials that connect harvesting and consuming traditional foods to promoting health were created or adapted, including calendars of seasonal foods, posters, and lesson plans. The medicine wheel nutrition intervention was tailored by several programs to illustrate the story of their food systems $(46,69)$.

- Emphasis on education: Sharing traditional foods recipes, cooking and preparing foods, participating in hands-on food demonstrations, and taste tests created learning opportunities in schools and clubs. Children experienced traditional foods as school cafeteria staples and commodity foods available through FDPIR. Some programs educated tribal members and interested allies (e.g., state and local 
government officials) about food sovereignty, engaging interested youth in creating digital stories about their work. To gather background to inform interventions, as well as to engage communities, one program developed a family meal survey that informed their food preparation educational sessions and was shared with partners. Several programs used the Food Sovereignty Assessment Tool developed by the First Nations Development Institute (70).

- Community-driven planning: Communities determined their needs and approaches with the help of advisory boards, community needs assessments and focus groups, interviews, and surveys among community members.

- Sustained efforts beyond the project's end: Programs sustained elements of their work after the cooperative agreement ended in September, 2014. Several programs secured support through their tribal councils to continue positions established by their program; several were awarded grants and contracts from university partnerships, state and county health departments, federal agencies (e.g., USDA and IHS), and nonprofit organizations.

\section{Conclusion}

Community collaboration to increase access to traditional foods, physical activity, and social support might have the potential to advance health initiatives across agencies and the country. For example, in 2011, Traditional Foods Project's partners offered insight to the Bureau of Indian Education as they developed their School Health and Wellness Policy supporting the provision for "healthy traditional and cultural foods" (71). Tribal schools also are providing hands-on learning activities about growing healthy foods. Sustainability of these activities is strengthened by local and national efforts, including the Farm to School initiative (72).

Native communities across the country are applying their traditional ecological knowledge, specific to the history and culture of their tribe, to protect their homelands of land, language, culture, memory, and traditional foods practices. Sharing and documenting food sovereignty efforts continues to be a priority. A collection of stories told by tribes about their traditional foods systems is published on the NDWP website (47). Underpinning the stories are long-sighted lessons for sustainability, steeped in cultural significance and emotional attachment (68) and inspired by agency (i.e., capacity of acting or of exerting power), self-determination, and hope, for the health of the people.

\section{Acknowledgments}

The CDC Native Diabetes Wellness Program recognizes the 17 tribal Traditional Foods Project partners that formed the cornerstone of the CDC Traditional Foods Project (2008-2014) program described in this report:

Aleutian Pribilof Islands Association (Alaska), The Aleut Diet Program; Catawba Cultural Preservation Project (South Carolina), Catawba Lifestyle and Gardening Project; Cherokee Nation (Oklahoma), Cherokee Nation Healthy Nation/Foods Project; Confederated Tribes of Siletz Indians (Oregon), Siletz Healthy Traditions Project; Eastern Band of Cherokee Indians (North Carolina), Healthy Roots for Healthy Futures; Indian Health Care Resource Center of Tulsa (Oklahoma), Building CommunityStrengthening Traditional Ties; Nooksack Indian Tribe (Washington), Listen to the Elders: Healing Nooksack Health Through History; Prairie Band Potawatomi Nation (Kansas), Return to a Healthy Past; Ramah Navajo School Board (New Mexico), Empowering Ramah Navajo to Eat Healthy by Using Traditional Foods; Red Lake Band of Chippewa Indians (Minnesota), Old Ways for Today's Health; Salish Kootenai College (Montana), Traditional Living Challenge and Ancestor's Choice; Santee Sioux Nation (Nebraska), Wiconi Unki Tawapi-Healing Our Lives; Sault Ste. Marie Tribe of Chippewa Indians (Michigan), Uniting to Create Traditional and Healthy Environments; Southeast Alaska Regional Health Care Consortium (Alaska), WISEFAMILIES Through Customary and Traditional Living; Standing Rock Sioux Tribe (North Dakota and South Dakota), Native Gardens Project: An Indigenous Permaculture Approach to the Prevention and Treatment of Diabetes; Tohono O'odham Community Action (Arizona), O'odham Ha'icu Ha-Hugi c Duakog: Tohonoo O'odham Food, Fitness \& Wellness Initiative Project; United Indian Health Services (California), Food is Good Medicine.

\section{References}

1. West KM. Diabetes in American Indians and other Native populations of the new world: Diabetes 1924;23:841-55.

2. Joslin EP. The universality of diabetes: a survey of diabetic mortality in Arizona. Diabetes 1940;115:2033-8.

3. Schulz LO, Bennett PH, Ravussin E, et al. Effects of traditional and western environments on prevalence of type 2 diabetes in Pima Indians in Mexico and the U.S. Diabetes Care 2006;29:1866-71. http://dx.doi. org/10.2337/dc06-0138.

4. Dabelea D, DeGroat J, Sorrelman C, et al.; SEARCH for Diabetes in Youth Study Group. Diabetes in Navajo youth: prevalence, incidence, and clinical characteristics: the SEARCH for Diabetes in Youth Study. Diabetes Care 2009;32(Suppl 2):S141-7. http://dx.doi.org/10.2337/ dc09-S206.

5. CDC. National Diabetes Statistics Report: Estimates of diabetes and its burden in the United States, 2014. Atlanta, GA: US Department of Health and Human Services; 2014. http://www.cdc.gov/diabetes/data/ statistics/2014StatisticsReport.html.

6. Centers for Disease Control and Prevention (CDC). Diagnosed diabetes among American Indians and Alaska Natives aged <35 years-United States, 1994-2004. MMWR Morb Mortal Wkly Rep 2006;55:1201-3.

7. Roberts H, Jiles R, Mokdad A, Beckles G, Rios-Burrows N. Trend analysis of diagnosed diabetes prevalence among American Indian/Alaska native young adults_-United States, 1994-2007. Ethn Dis 2009;19:276-9. 
8. Gilliland SS, Carter JS, Skipper B, Acton KJ. HbA(1c) levels among American Indian/Alaska Native adults. Diabetes Care 2002;25:2178-83. http://dx.doi.org/10.2337/diacare.25.12.2178.

9. National Center for Health Statistics. National Health Interview Survey Data Brief. Prevalence of obesity among adults and youth, United States. No. 219, November 2015.

10. CDC. Obesity among low-income preschool children. Atlanta, GA: US Department of Health and Human Services; 2015. http://www.cdc.gov/ obesity/downloads/PedNSSFactSheet.pdf.

11. Penman-Aguilar A, Boye K, Liburd L. Background and rationale. In: Strategies to reduce health disparities: selected CDC-sponsored interventions-United States, 2016. MMWR Suppl 2016;65(No. Suppl 1).

12. Salmon CT. Bridging theory "of" and theory "for" communicationcampaigns: an essay on ideology and public policy. In: Deertz SA (ed). Comm Yearbook, Sage: Newbury Park CA, 1992.

13. Krieger N. Sticky webs, hungry spiders, buzzing flies, and fractal metaphors: on the misleading juxtaposition of "risk factor" versus "social" epidemiology. J Epidemiol Community Health 1999;53:678-80. http:// dx.doi.org/10.1136/jech.53.11.678.

14. Kunitz SJ. Disease and social diversity: The European impact on the health of non-Europeans 1994. New York: Oxford University Press.

15. Brave Heart MY, DeBruyn LM. The American Indian Holocaust: healing historical unresolved grief. Am Indian Alsk Native Ment Health Res 1998;8:56-78.

16. CDC. Injury prevention and Control: Division of Violence Prevention, Adverse childhood experiences (ACE) Study. http://www.cdc.gov/ violenceprevention/acestudy.

17. Danese A, Tan M. Childhood maltreatment and obesity: systematic review and meta-analysis. Mol Psychiatry 2014;19:544-54. http://dx.doi. org/10.1038/mp.2013.54.

18. Burke NJ, Hellman JL, Scot BG, Weems CF, Carrion VG. The implications of adverse childhood experiences on an urban pediatric population. Child Abuse Negl 2011;35:791-803. http://dx.doi.org/ 10.1016/j.chiabu.2011.02.006.

19. Williamson DF, Thompson TJ, Anda R, Dietz WH, Felliti VJ. Body weight, obesity, and self-reported abuse in childhood. Int J Obes Relat Metab Disorder 2011;35:408-13.

20. Felitti VJ, Anda RF, Nordenberg D, et al. Relationship of childhood abuse and household dysfunction to many of the leading causes of death in adults. The Adverse Childhood Experiences (ACE) Study. Am J Prev Med 1998;14:245-58. http://dx.doi.org/10.1016/S0749-3797(98)00017-8.

21. Shonkoff JP, Garner AS, Siegel BS, et al.; Committee on Psychosocial Aspects of Child and Family Health; Committee on Early Childhood, Adoption, and Dependent Care; Section on Developmental and Behavioral Pediatrics. The lifelong effects of early childhood adversity and toxic stress. Pediatrics 2012;129:e232-46. http://dx.doi.org/10.1542/ peds.2011-2663.

22. Brockie TN, Heinzelmann M, Gill J. A framework to examine the role of epigenetics in health disparities among Native Americans. Nurs Res Prac 2013. http://www.ncbi.nlm.nih.gov/pubmed/24386563.

23. Bullock A. Getting to the roots: early life intervention and adult health. Am J Psychiatry 2015;172:108-10. http://dx.doi.org/10.1176/appi. ajp.2014.14111394.

24. U.S. Department of Health and Human Services. Social determinants of health. Healthy People 2020. http://www.healthypeople.gov/2020/ topics-objectives/topic/social-determinants-health\#five.

25. U.S. Department of Interior. American Indian population and labor force report, 2013. Washington, DC: Bureau of Indian Affairs, 2014.

26. Gordon A, Oddo V. Addressing child hunger and obesity in Indian Country: Report to Congress. Alexandria, VA: Office of Research and Evaluation. Food and Nutrition service, 2012. http://www.fns.usda.gov/ ora/MENU/Published/CNP/FILES/IndianCountry.pdf.

27. Nackers LM, Appelhans BM. Food insecurity is linked to a food environment promoting obesity in households with children. J Nutr Educ Behav 2013;45:780-4. http://dx.doi.org/10.1016/j.jneb.2013.08.001.
28. Seligman HK, Bindman AB, Vittinghoff E, Kanaya AM, Kushel MB. Food insecurity is associated with diabetes mellitus: results from the National Health Examination and Nutrition Examination Survey (NHANES) 1999-2002. J Gen Intern Med 2007;22:1018-23 http:// dx.doi.org/10.1007/s11606-007-0192-6.

29. Seligman HK, Jacobs EA, López A, Tschann J, Fernandez A. Food insecurity and glycemic control among low-income patients with type 2 diabetes. Diabetes Care 2012;35:233-8. http://dx.doi.org/10.2337/dc11-1627.

30. Berkowitz SA, Baggett TP, Wexler DJ, Huskey KW, Wee CC. Food insecurity and metabolic control among U.S. adults with diabetes. Diabetes Care 2013;36:3093-9. http://dx.doi.org/10.2337/dc13-0570.

31. United States Department of Agriculture. Food deserts. https://apps. ams.usda.gov.

32. Mullany B, Neault N, Tsingine D, et al. Food insecurity and household eating patterns among vulnerable American-Indian families: associations with caregiver and food consumption characteristics. Public Health Nutr 2013;16:752-60. http://dx.doi.org/10.1017/S136898001200300X.

33. Bauer KW, Widome R, Himes JH, et al. High food insecurity and its correlates among families living on a rural American Indian Reservation. Am J Public Health 2012;102:1346-52. http://dx.doi.org/10.2105/ AJPH.2011.300522.

34. Echo Hawk Consulting. Feeding ourselves: Food access, health disparities, and the pathways to healthy Native American communities. Longmont, CO: Echo Hawk Consulting, 2015.

35. Nazarea VD. Ethnoecology as situated knowledge. In: Nazarea VD, (ed.), Ethnoecology: situated knowledge, located lives. Tucson, AZ: Univ. of Arizona Press, 1999.

36. Bird ME. Health and indigenous people: recommendations for the next generation. Am J Public Health 2002;92:1391-2. http://dx.doi.org/10.2105/ AJPH.92.9.1391.

37. Liburd LC. Diabetes and health disparities: community-based approaches for racial and ethnic populations. New York: Springer Publishing Co. 2011:257-74.

38. Johns T. Plant constituents and the nutrition and health of indigenous peoples. In V.D. Nazarea (Ed.), Ethnoecology: Situated knowledge, located lives. Tucson, AZ: Univ. of Arizona Press, 1999.

39. Joos SK. Economic, social, and cultural factors in the analysis of disease: dietary changes and diabetes mellitus among the Florida Seminole Indians. In: Brown LK, Mussell K, (ed). Ethnic and regional foodways in the U.S.: The performance of group identity (4th ed). Knoxville, TN: University Tennessee Press 1984:217-37.

40. McLaughlin S. Traditions and diabetes prevention: a healthy path for Native Americans. Diabetes Spectrum 2010;23:272-77.

41. Sevilla G. A people in peril: Pimas on the front lines of an epidemic. The Arizona Republic, Oct. 31, 1999.

42. Williams DE, Knowler WC, Smith CJ, et al. The effect of Indian or Anglo dietary preference on the incidence of diabetes in Pima Indians. Diabetes Care 2001;24:811-6. http://dx.doi.org/10.2337/diacare.24.5.811.

43. Jones L. A dam brings a flood of diabetes to three tribes. Indian Country Today, July 5, 2011. http://indiancountrytodaymedianetwork. com/2011/07/a-dam-brings-a-flood-of-diabetes-to-three-tribes.

44. State of North Dakota and North Dakota Department of Public Instruction. The History and Culture of the Standing Rock Oyate. Bismarck, N.D.: Department of Public Instruction, 1995.

45. Satterfield D, Eagle Shield J, Buckley J, Taken Alive V. "So that the people may live (Hecel lena oyate ki nipikte):" Lakota and Dakota elder women as reservoirs of life and keepers of knowledge about health protection and diabetes prevention. J Health Dispar Res Pract 2007;2:1-28.

46. Conti KM. Diabetes prevention in Indian country: developing nutrition models to tell the story of food-system change. J Transcult Nurs 2006;17:234-45. http://dx.doi.org/10.1177/1043659606288380.

47. Burrows NR, Geiss LS, Engelgau MM, Acton KJ. Prevalence of diabetes among Native Americans and Alaska Natives, 1990-1997: an increasing burden. Diabetes Care 2000;23:1786-90. http://dx.doi.org/10.2337/ diacare.23.12.1786. 
48. Satterfield D, DeBruyn L, Dodge Francis C, Allen A. A stream is always giving life: Communities reclaim traditional ways to prevent diabetes and promote health. Am Indian J Culture Research 2014;38:157-90. http://dx.doi.org/10.17953/aicr.38.1.hp318040258r7272.

49. CDC. Wesner C. Traditional foods in Native America: A compendium of stories from the indigenous food sovereignty movement in American Indian and Alaska Native communities. Atlanta GA: Native Diabetes Wellness Program, CDC. http://www.cdc.gov/diabetes/projects/ndwp/ traditional-foods.htm.

50. Patel R. Food sovereignty. J Peasant Stud 2009;35:663-706. http:// dx.doi.org/10.1080/03066150903143079.

51. International Indian Treaty Council. An analysis of US international policy on indigenous people: The human right to food and food security. 2002. http://www.iitc.org/program-areas/treaties-standard-setting.

52. Act BB. (BBA) of 1997, Public Law 105-33. 105th Congress. https:// www.congress.gov/bill/105th-congress/house-bill/2015.

53. Sequist TD, Cullen T, Acton KJ. Indian health service innovations have helped reduce health disparities affecting american Indian and alaska native people. Health Aff (Millwood) 2011;30:1965-73. http://dx.doi. org/10.1377/hlthaff.2011.0630.

54. Indian Health Service. Special Diabetes Program for Indians Report to Congress 2011. Division of Diabetes Treatment and Prevention. http:// www.ihs.gov/MedicalPrograms/Diabetes/index.cfm? module= programsSDPIRTC.

55. United States Renal Data System. 2015 USRDS annual data report: Epidemiology of kidney disease in the United States. Bethesda, MD: National Institutes of Health, National Institute of Diabetes and Digestive and Kidney Diseases, 2015. http://www.usrds.org/2015/view/v2_01.aspx.

56. Tervalon M, Murray-García J. Cultural humility versus cultural competence: a critical distinction in defining physician training outcomes in multicultural education. J Health Care Poor Underserved 1998;9:11725. http://dx.doi.org/10.1353/hpu.2010.0233.

57. Blue Bird Jernigan V, Peercy M, Branam D, et al. Beyond health equity: achieving wellness within American Indian and Alaska Native communities. Am J Public Health 2015;105(Suppl 3):S376-9. http:// dx.doi.org/10.2105/AJPH.2014.302447.

58. Mariella P, Brown E, Carter M, Verri V. Tribally-driven participatory research: state of the practice and potential strategies for the future. J Health Dispar Res Pract 2009;3:41-58.
59. Laveaux D, Christopher S. Contextualizing CBPR: Key Principles of CBPR meet the Indigenous research context. Pimatisiwin 2009;7:1-25.

60. CDC. Native Diabetes Wellness Program. Eagle Books. http://www. cdc.gov/diabetes/projects/diabetes-wellness.htm.

61. Aho L, Ackerman J, Bointy S, et al. Health is life in balance: Students and communities explore health lifestyles in a culturally-based curriculum. Pimatisiwin 2011;8:151-68.

62. Dodge-Francis C, Coulson D, Kalberer B, DeBruyn L, Freeman W, Belcourt J. The significance of a K-12 Diabetes-based Science Education Program for tribal populations: Evaluating cognitive learning, cultural context, and attitudinal components. J Health Dispar Res Pract 2010;3:91-105.

63. Moore K, Dodge-Francis K, DeBruyn L. American Indian Higher Education Consortium "Honoring Our Health," grant program. In: Liburd LC, (ed). Diabetes and health disparities: community-based approaches for racial and ethnic populations. New York, Springer Pub, 2011:257-74

64. McLulan TC. The way of the earth: encounters with nature in ancient and contemporary thought. 1994. New York: Simon and Schuster, 1994:70.

65. The Agricultural Act of 2014. HR 2642. 113th Congress. Public Law 113-79. Title IV, Section 4004, 4028, 4033.

66. United States Department of Agriculture. Food Distribution Program on Indian Reservations Fact Sheet 2014. www.fns.usda.gov/www.fns. usda.gov/site/default/files/pfs.fdpir.pdf.

67. Unger S. Qaqamiigux: Traditional foods and recipes from the Aleutian and Pribilof Islands nourishing our mind, body and spirit for generations. Anchorage, AK: Aleutian Pribilof Islands Association, 2014.

68. Nazarea VD, Rhoades RE, Andrews-Swann JE. Seeds of resistance, seeds of hope: Place and agency in the conservation of biodiversity. Tucson, AZ: Univ ArizPress, 2013:5.

69. Kattelmann KK, Conti K, Ren C. The medicine wheel nutrition intervention: a diabetes education study with the Cheyenne River Sioux Tribe. J Am Diet Assoc 2009;109:1532-9. http://dx.doi.org/10.1016/j. jada.2009.06.362.

70. First Nations Development Institute. Food Sovereignty Assessment Tool (2nd ed), 2014. http://www.firstnations.org/knowledge-center/foodshealth/FSAT-2nd-Ed.

71. Bureau of Indian Education. Indian Affairs Manual. Washington, DC, 2012. 72. National Farm to School Network. http://www.farmtoschool.org. 